\title{
Screening of Potent Laccase Producing Organisms Based on the Oxidation Pattern of Different Phenolic Substrates
}

\author{
Sheena Devasia* and A. Jayakumaran Nair \\ Department of Biotechnology, University of Kerala, Kariavattom, Trivandrum, Kerala, India \\ *Corresponding author
}

\section{A B S T R A C T}

Keywords

Arthrographis, bacterial laccase, Enterobacter cloacae, guaiacol, laccase, lignin, oxidoreductase.

\section{Article Info}

Accepted:

12 April 2016 Available Online: 10 May 2016
Soil samples were collected from different forest areas of Kerala and screened for laccase activity using guaiacol plate assay technique. An increased concentration of guaiacol was used for the isolation of resistant strains. Substrate oxidation studies were carried out and the potent organisms were taken for enzyme production studies. The organisms, isolated by the screening strategies, were found efficient laccase producers. The potent organisms were identified as Arthrographis sp. and Enterobacter cloacae. The enzyme production rate of Arthrographis was found to increase logarithmically and a maximum quantity of $53 \mathrm{U} / \mathrm{ml}$ was obtained and the bacterial strain, Enterobacter cloacae, gave a maximum laccase activity of $8 \mathrm{U} / \mathrm{ml}$. The difference in the pattern of substrate oxidation by laccase from different organisms is paid attention in the study.

\section{Introduction}

Laccases (benzenediol: oxygen oxidoreductase, EC 1.10.3.2) catalyze the oxidation of various aromatic, particularly phenolic substrates (eg. hydroquinone, guaiacol, 2,6-dimethoxyphenol or phenylene diamine), coupled to the reduction of molecular oxygen to water. Laccases as well as ascorbate oxidases (EC 1.10.3.3) and ceruloplasmins/ferroxidase (EC 1.16.3.1) usually contain several copper atoms in the catalytic centre. They belong to the enzyme superfamily of multicopper oxidases, which is a widely distributed protein family among prokaryotes and eukaryotes. However, laccases or laccase-like multicopper oxidases (LMCO) were predominantly described in fungi and plants, where they occur as multigene family with sometimes more than 10 different laccase genes. The basidiomycete Coprinopsis cinerea and the plant Arabidopsis thaliana have both 17 different genes (Hoegger et al., 2006).

\section{Properties of Laccases}

Current knowledge about the structure and physico-chemical properties of fungal proteins is based on the study of purified proteins. Up to now, more than 100 laccases have been purified from fungi and been more or less characterized. The laccase 
molecule, as an active holoenzyme form, is a dimeric or tetrameric glycoprotein, usually containing four copper per monomer $(\mathrm{Cu})$ atoms bound to three redox sites (Type 1, Type 2 and Type $3 \mathrm{Cu}$ pair). The molecular mass of the monomer ranges from about 50 to $100 \mathrm{kDa}$ with acidic isoelectric point around $\mathrm{pH}$ 4.0. An important feature is the high level of glycosylation (with covalently linked carbohydrate moieties ranging from $10-50 \%$ of the total weight, depending on the species or the heterologous host), which may contribute to the high stability of the enzyme (Duran et al., 2002). Several laccase isoenzymes have been detected in many fungal species. More than one isoenzyme is produced in most white-rot fungi.

In contrast to most enzymes, which are generally very substrate specific, laccases act on a surprisingly broad range of substrates, including diphenols, polyphenols, different substituted phenols, diamines, aromatic amines and benzenethiols. Furthermore, laccases with unusual and potentially useful properties have been isolated from ascomycetes. Laccase from Monocillium indicum was the first laccase to be characterized from as ascomycetes showing peroxidative activity (Thakker et al., 1992). Examples include the higher stability and activity at alkaline $\mathrm{pH}$ together with the high thermostability of the laccase produced by Melanocarpus albomyces (Kiiskinen et al., 2002), the high acid tolerance of intracellular laccase from Hortaea acidophila (Tetsch et al., 2006), and the high activity of laccase from Xylaria polymorpha at elevated concentrations of $\mathrm{NaCl}$ (Liers et al., 2007). It was postulated that laccase acts as a defense mechanism against oxidative stress (Fernandez-Larrea and Stahl, 1996). This protective function was partly attributed to the chelation of copper ions during synthesis of the laccase enzyme.

\section{Substrates and Products formed by Laccase}

Laccase has broad substrate specificity as well as the advantage of not requiring an addition of harmful hydrogen peroxide to the oxidative reaction. Because of complex structure of lignin, its biodegradation system is considered highly nonspecific. Lignolytic enzymes can degrade environmental pollutants that differ structurally (Dec and Bollag, 1994). The substrate oxidation pattern of laccase is tabulated in Table 1.

\section{Materials and Methods}

Soil samples were collected from different forest areas of Kerala and screened for laccase activity. The serially diluted soil samples were inoculated on Vogel's Mineral Media (VMM) agar plates ( $\mathrm{pH}$ 5.6) containing guaiacol (Di- methoxy phenol) (Sigma) as substrate (Vogel, 1956; Coll et $a l .$, 1993). The positive strains were purified and modified plate assay for selecting high tolerance laccase producing strains was conducted using an increased concentration of guaiacol.

\section{Substrate Oxidation Studies by Laccase}

The substrate tolerance was studied by incorporating $0.02 \%$ of guaiacol, p-cresol, paminophenol, p-phenylene diamine, hydroquinone and tropolone in VMM agar plates. The fungal plates were incubated at $27 \pm 1^{\circ} \mathrm{C}$ for 5 days and the bacterial plate was incubated for $48 \mathrm{~h}$ at $37^{\circ} \mathrm{C}$. The growth and oxidation pattern were noted.

\section{Organisms and Culture Conditions}

\section{Preparation of Pre-inoculum}

Pre inoculum was prepared by inoculating VMM agar plates for fungi and VMM broth 
for bacteria. Agar plugs from the outer circumference of a fungal colony stored on a SDA plate was used as the inoculum. The fungal strains were inoculated to VMM plates and were incubated for 6 days at $27 \pm 1^{\circ} \mathrm{C}$. The bacterial strain was inoculated from NA slant to VMM broth and was incubated for $24 \mathrm{~h}$ at $120 \mathrm{rpm}, 37^{\circ} \mathrm{C}$.

\section{Preparation of Inoculum}

Agar plugs (5 mm diameter) from the outer circumference of fungal colonies growing on VMM plate (8 days) was used as inoculum for fungal production media and $1 \%$ bacterial culture with $0.7 \mathrm{Abs}$ at $600 \mathrm{~nm}$ was used for inoculating the bacterial production media.

\section{Activity Based Secondary Screening of Organisms}

Laccase production was carried out in VMM broth, $\mathrm{pH}$ 5.6. The fungal cultures were incubated at $27 \pm 1^{\circ} \mathrm{C}$ and the bacterial culture at $37^{\circ} \mathrm{C}$. The samples were collected in every $24 \mathrm{~h}$ and centrifuged at 10,000 rpm for $15 \mathrm{~min}$. The supernatant was taken for enzyme assay. The enzyme assay was conducted using 2,2'-azino-bis (3ethylbenzothiazoline-6-sulphonic acid (ABTS) (Biogene, USA) as substrate.

The assay mixture contained $2 \mathrm{mM}$ ABTS in $0.1 \mathrm{M}$ sodium citrate buffer, $\mathrm{pH}$ 3.0. Oxidation of ABTS was monitored by determining the absorbance increase at 420 $\mathrm{nm}\left(\varepsilon=3.6 \times 10^{4} \mathrm{M}^{-1} \mathrm{~cm}^{-1}\right)(\mathrm{Jia} \mathrm{Li}$ Dong, 2004). One unit of enzyme activity was defined as the amount of enzyme required to oxidize $1 \mu \mathrm{mol}$ of ABTS per min. Assay was conducted at regular intervals. The laccase production rate and the optimum day of enzyme production were noted for each of the selected organisms. Statistical model was constructed based on enzyme activity and day of incubation.

\section{Tolerance Assay}

The $K S F_{2}$ strain was subjected to substrate tolerance assay. $1 \mathrm{mM}$ concentration of the phenolic substrates ( $p$-cresol, $p$-aminophenol and $p$-phenylene diamine, guaiacol, hydroquinone and tropolone) were added to VMM broth, $K S F_{2}$ culture was inoculated and incubated at $27 \pm 1^{\circ} \mathrm{C}$ at $120 \mathrm{rpm}$. The oxidation of the substrate and the tolerance pattern was noted in broth cultures. The laccase assay was conducted at regular intervals using ABTS as substrate

The potent strains selected were sent to IMTECH, Chandigarh, India for identification.

\section{Results and Discussion}

\section{Pure Culture Isolation}

Soil samples were plated on to guaiacol containing medium. Oxidation polymerization of guaiacol to bisphenoquinone was visualized as reddish brown zones on VMM agar plates (Fig. 1). Efficient and potent organisms screened by this method were purified and inoculated to the respective agar plates to study the colony morphology (Fig. 2). Of the 41 isolated strains isolated by this technique, 4 strains were selected after the primary screening studies. Out of the 4 strains, 3 were fungi $\left(\mathrm{KSF}_{1}, \mathrm{KSF}_{2}\right.$ and $\left.\mathrm{KSF}_{3}\right)$ and the other one was bacteria, $\mathrm{KSB}_{4}$.

\section{Modified Plate Assay for High Tolerance Laccase Producing Strains}

Potent DMP tolerant laccase producing organisms were isolated by this technique. The concentration of guaiacol in the plates was increased to $0.04 \%$ to find the tolerance of the organisms. All the organisms could grow in the increased concentration of 
guaiacol and oxidize the substrate. The fungal colonies were incubated for 5 days at $27^{\circ} \mathrm{C}$ and the bacterial colony was incubated for $48 \mathrm{~h}$ at $37^{\circ} \mathrm{C}$. The bacterium was found to be less tolerant to the increased concentration of the substrate as after incubation period the viability of the organism decreased to considerable extends (Fig.3).

\section{Substrate Oxidation Pattern of the Isolated Strains}

Out of the six compounds selected for the study guaiacol was oxidized by all the selected strains. $\mathrm{KSF}_{1}$ could grow in the presence of $\mathrm{p}$-cresol, $\mathrm{p}$-aminophenol and hydroquinone but could not oxidize the compounds. $\mathrm{KSF}_{2}$ could grow in the presence of all substrates except tropolone and could oxidize p-phenylene diamine. $\mathrm{KSF}_{3}$ could not grow in the presence of any of the substrates. KSB4 and $\mathrm{KSF}_{2}$ could grow on all substrates except tropolone and could oxidize p-phenylene diamine and hydroquinone. Results are tabulated in Table 2. The oxidation reaction is presented in Fig. 4. The level of tolerance was directly proportional to the amount of laccase produced by the organisms.

The potent strain, $K S F_{2}$ was inoculated to the VMM agar plates supplemented with the assay substrates (guaiacol, catechol and ABTS) to confirm the best substrate for laccase assay. The plates are incubated at $27 \pm 1^{\circ} \mathrm{C}$ for 5 days. It was observed that the laccase of $K S F_{2}$ was more reactive to ABTS (Fig. 5).

\section{Activity Based Secondary Screening of Organisms}

The organisms were inoculated into VMM broth for laccase production and ABTS assay was conducted every $24 \mathrm{~h}$ to find the optimum day of enzyme production. The quantity of enzyme produced by the strains, enzyme production pattern and the optimum day of enzyme production by each organism also differed.

The results are tabulated in Table 3 and Fig. 6 . The enzyme production rate of $\mathrm{KSF}_{2}$ was found to increase logarithmically till $102^{\text {nd }}$ day of inoculation. From this secondary screening method $\mathrm{KSF}_{2}$ and $\mathrm{KSB}_{4}$ were screened as the most potent strains for laccase production.

Results indicate that the laccase production is high in the exponential growth phase; the activity appears to be closely correlated with biomass production. Different strains can produce different laccases, each with its own unique features. Environmental factors influence the ability of fungi to produce high titers of laccase, and different strains react differently to these conditions. Screening of strains capable of producing high concentrations of enzyme and then to optimize the conditions for laccase production is important in the industrial production of the enzymes.

\section{Statistical Model Construction Based on Enzyme Activity and Day of Incubation}

Different statistical models were tried to find the correct fitted model to explain the enzyme activity when day was set as the variable (Fig. 7). The model for which the coefficient of determination (R2) is maximum, was selected as the best suited model. It was observed that the cubic model was best suited to explain the enzyme activity by the isolated strains.

The tolerance of the organism in $\mathrm{SmF}$ is tried for its application studies. In $1 \mathrm{mM}$ concentration of the substrates $K S F_{2}$ was able to grow in broths supplemented with $p$ aminophenol and $p$-phenylene diamine and 
was also able to oxidize them. $p$ aminophenol was not oxidized by the organism in plate assay method. The enhanced production of laccase in shaking condition attributed to the oxidation of $p$ aminophenol.

All the other substrates inhibited the growth of the organism in broth culture. The oxidation of the two substrates was visualized in broths and the laccase assay was conducted to study the effect of the presence of these compounds on enzyme production. The ABTS assay was conducted for the media with $p$-phenolic compounds. The culture was inoculated to modified VMM minimal media and was kept as control. There was a decrease in laccase activity observed in the presence of phenolic compounds.

\section{Morphological and Biochemical Identification of Organisms}

The Ascomycetes strain $K S F_{2}$ was identified as Arthrographis sp. by IMTECH, Chandigarh, India and was deposited with reference MTCC 8880. It has branched, hyaline conidiophores, thallic and arthric conidiogenesis and hyaline single celled conidia in dry chains (Fig 8). The bacterial strain $\mathrm{KSB}_{4}$ was identified as Enterobacter cloacae by IMTECH, Chandigarh, India and was deposited with reference MTCC 9145.

Table.1 Substrate oxidation pattern of laccase

\begin{tabular}{|l|l|l|l|l|}
\hline Substrate & Product & Colour & $\begin{array}{l}\boldsymbol{\lambda} \mathbf{m a x} \\
(\mathbf{n m})\end{array}$ & $\begin{array}{c}\boldsymbol{\varepsilon}_{\max } \\
\left(\mathbf{M}^{-1} \mathbf{c m}^{-1} \mathbf{~}\right.\end{array}$ \\
\hline Catechol & $o$-benzoquinone & Yellow & 450 & 2,211 \\
\hline Hydroquinone & $o$-benzoquinone & Yellow & 248 & 17,252 \\
\hline Pyrogallol & Purpurogallin & Yellow & 450 & 4,400 \\
\hline 2,6 dimethoxy phenol & $3,5,3^{\prime}, 5^{\prime}$ tetramethoxy diphenoquinone & Yellow & 468 & 35,645 \\
\hline Guaiacol & Biphenoquinone & Brown & 470 & 26,600 \\
\hline ABTS & ABTS & Blue & 420 & 36,000 \\
\hline Syringaldazine & Quinones & Purple & 525 & 65,000 \\
\hline Catechin & $o$-quinone & Yellow & 390 & 4,019 \\
\hline
\end{tabular}

Table.2 Oxidation Pattern of Phenolic Compounds by the Screened Organisms

\begin{tabular}{|l|c|c|c|c|}
\hline \multirow{2}{*}{ Substrates } & \multicolumn{4}{|c|}{ Growth/ Oxidation Pattern } \\
\cline { 2 - 5 } & $K S F_{1}$ & $K S F_{2}$ & $K S F_{3}$ & $K S B_{4}$ \\
\hline guaiacol & $+/+$ & $+/+$ & $+/+$ & $+/+$ \\
\hline $\boldsymbol{p}$-cresol & $+/-$ & $+/-$ & $-/-$ & $+/-$ \\
\hline $\boldsymbol{p}$-aminophenol & $+/-$ & $+/-$ & $-/-$ & $+/-$ \\
\hline $\boldsymbol{p}$-phenylene diamine & $-/-$ & $+/+$ & $-/-$ & $+/+$ \\
\hline hydroquinone & $+/-$ & $+/-$ & $-/-$ & $+/+$ \\
\hline tropolone & $-/-$ & $-/-$ & $-/-$ & $-/-$ \\
\hline
\end{tabular}


Table.3 Enzyme Activity of the Isolated Strains

\begin{tabular}{|c|c|c|}
\hline Organism & Optimum day & $\begin{array}{c}\text { Enzyme activity } \\
\text { (U/L) }\end{array}$ \\
\hline$K S F_{1}$ & 31 & 155 \\
\hline$K S F_{2}$ & 102 & 52,764 \\
\hline$K S F_{3}$ & 15 & 15 \\
\hline$K S B_{4}$ & 5 & 8,317 \\
\hline
\end{tabular}

Fig.1 Plate Assay of Laccase
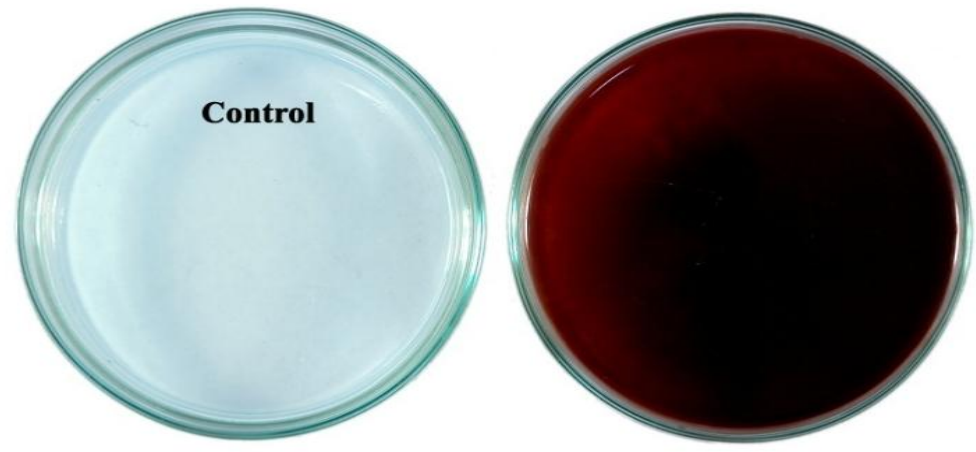

Fig.2 Cultural Characteristics of Isolated Strains on Agar Media
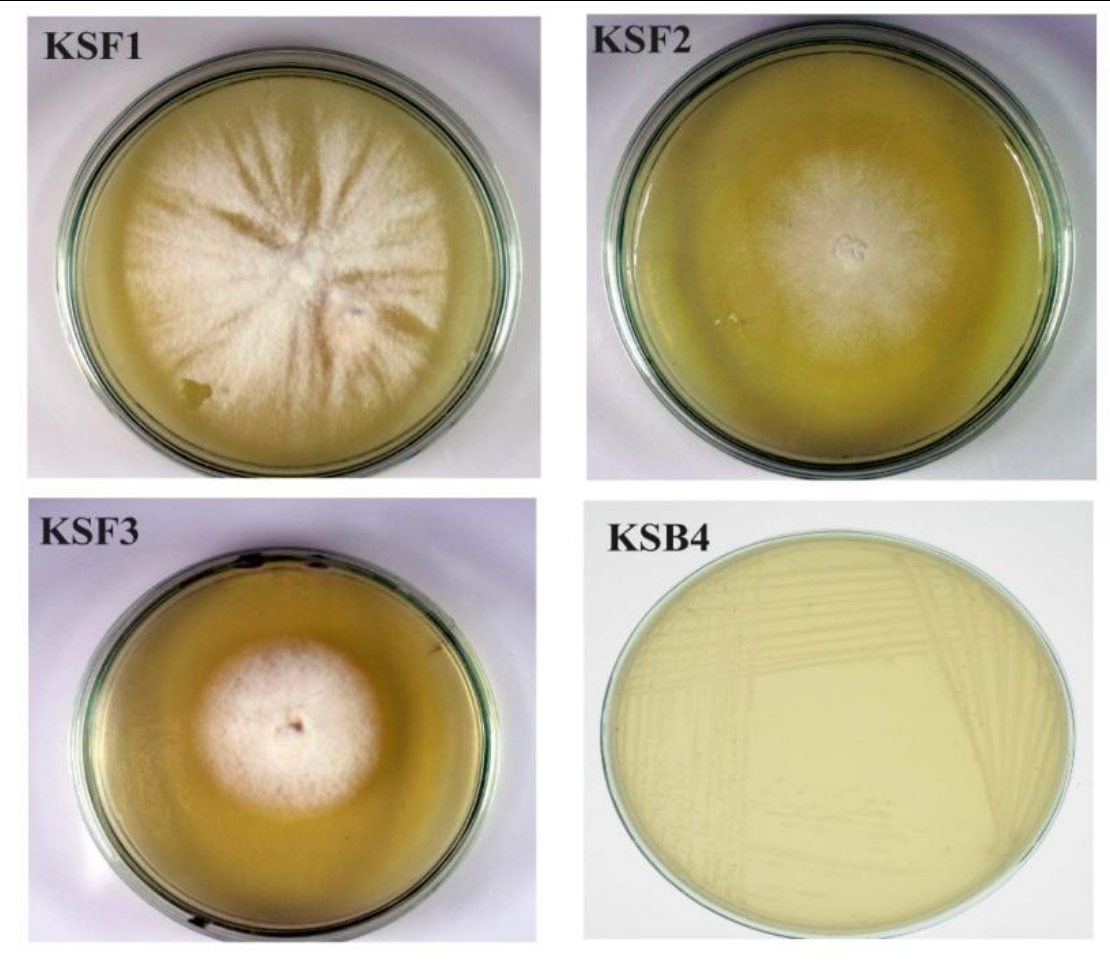
Fig.3 Modified Plate Assay for Laccase

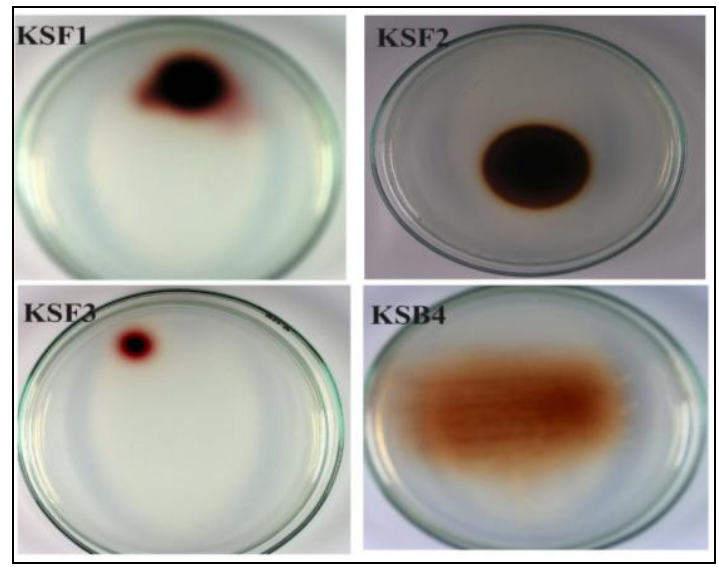

Fig.4 Oxidation of the Phenolic Compounds by the Potent Strains

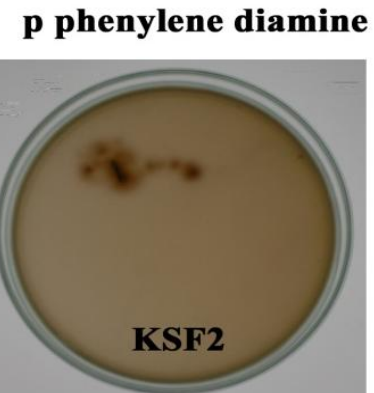

Hydroquinone

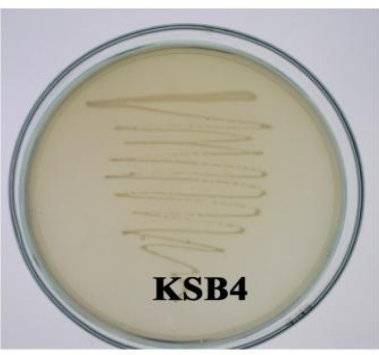

p phenylene diamine

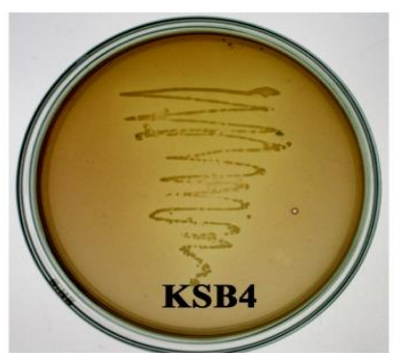

Fig.5 Oxidation of the Assay Substrates by $\mathrm{KSF}_{2}$

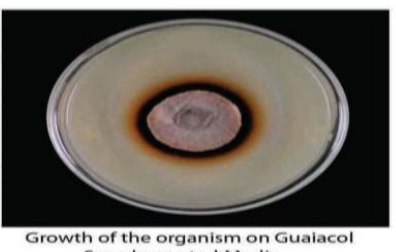
Supplemented Media

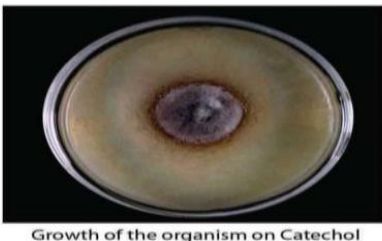

Growth of the organism on Catecho Supplemented Media

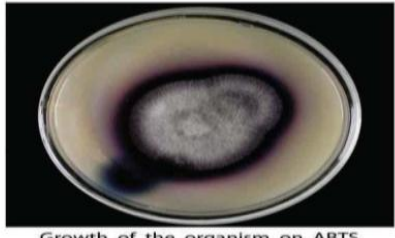

Growth of the organism on $\mathrm{ABTS}$ Supplemented Media

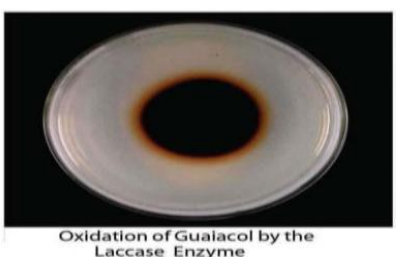

Laccase Enzym

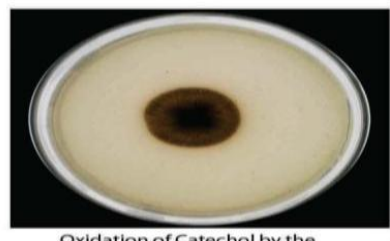

Oxidation of Catechol by the
Laccase Enzyme

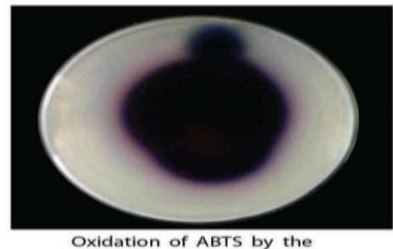

Oxidation of ABTS by the 
Fig.6 Laccase Production by the Strains
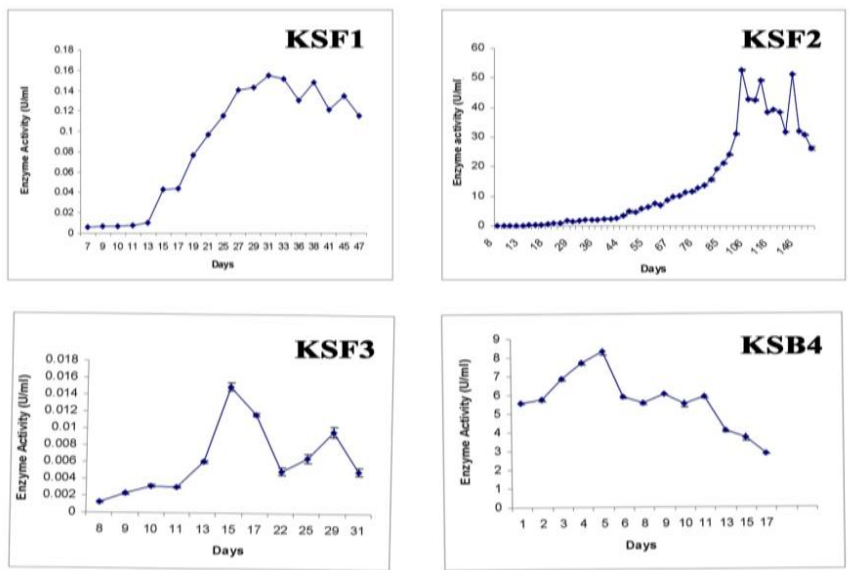

Fig.7 Statistical Models Based on Enzyme Production Pattern
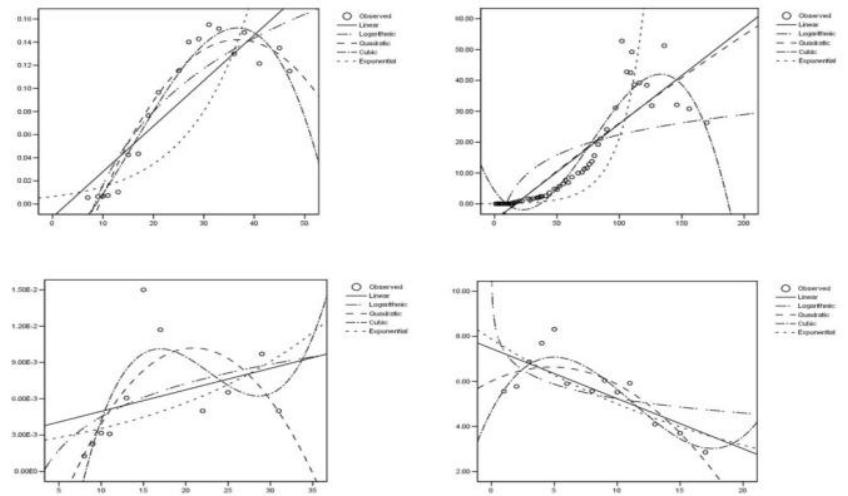

Fig.8 Lactophenol Cotton Blue Staining of Slide Culture

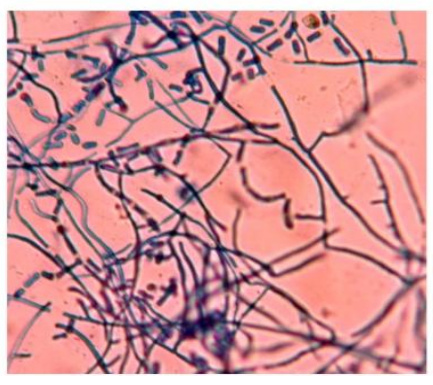

The selected potent strains can grow in the presence of guaiacol, p-cresol, paminophenol, p-phenylene diamine and hydroquinone explains their remarkable potential for application in bioremediation and wastewater treatment, especially in

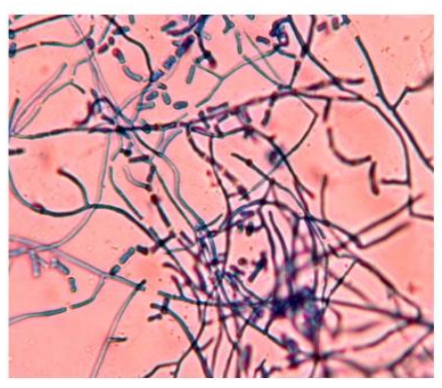

detoxification of phenolic wastes.

The organisms, isolated by the screening strategies, were found efficient laccase producers. The enzyme production rate of Arthrographis $\mathrm{KSF}_{2}$ was found to increase 
logarithmically and a maximum quantity of $53 \mathrm{U} / \mathrm{ml}$ was obtained on the $102 \mathrm{nd}$ day of inoculation. The bacterial strain, Enterobacter cloacae $\mathrm{KSB}_{4}$, was also found promising with a maximum laccase production of $8 \mathrm{U} / \mathrm{ml}$. Laccases from ascomycetes and bacteria has been paid only less attention, although they have unusual and potential biotechnological use, hence from the primary and secondary screening studies conducted the ascomycetes, Arthrographis $\mathrm{KSF}_{2}$ and the proteobacteria, Enterobacter cloacae $\mathrm{KSB}_{4}$ were selected for further studies.

The lignolytic enzymes: lignin peroxidase (LiP), manganese peroxidase $(\mathrm{MnP})$ and laccase completely biodegrade lignin polymers. The biological treatment of industrial wastewaters usually depends upon the oxidative activities of microorganisms. These enzymes do environmental clean up by oxidative degradation (Tanaka et al., 2001). These are extracellular enzymes that may be usefully engineered to improve the efficiency of particular bioremediation processes. These enzymes can reduce the concentration of selected phenolic compounds in refinery wastewater. Laccases from fungi have been shown to be useful for the degradation of a variety of persistent environmental pollutants.

Discovery of novel laccases with different substrate specificities and improved stabilities is important for industrial applications. Microbes that produce laccases are screened on solid media containing coloured indicator compounds that enable the visual detection of laccase production (Nishida et al., 1988; De Jong et al., 1992; Barbosa et al., 1996) or in liquid cultivations monitored with enzyme activity measurements (Luterek et al., 1997). The use of coloured indicators is generally simpler as no sample handling and measurement is required. As laccases oxidize various types of substrates, several different compounds have been used as indicators for laccase production. The traditional screening reagents tannic and gallic acid (Harkin and Obst, 1973) have nowadays mostly been replaced with synthetic phenolic reagents, such as guaiacol and syringaldazine (Nishida et al., 1988; De Jong et al., 1992) or with the polymeric dyes Remazol Brilliant Blue R (RBBR) and Poly R-478 (Barbosa et al., 1996; D'Souza et al., 1999; Raghukumar et al., 1999). RBBR and Poly R-478 are decolourized by lignindegrading fungi (Gold et al., 1988; Barbosa et al., 1996), and the production of ligninolytic enzymes is observed as a colourless halo around microbial growth. With guaiacol a positive reaction is indicated by the formation of a reddishbrown halo (Nishida et al., 1988), while with tannic and gallic acid the positive reaction is a dark-brown coloured zone (Harkin and Obst, 1973). These studies show that novel laccase producers can be discovered from environmental samples by very simple plate-test screening methods.

\section{References}

Barbosa, A.M., Dekker, R.F.H., Hardy, G.E. 1996. Veratryl alcohol as an inducer of laccase by an ascomycete, Botryo sphaeria, when screened on the polymeric dye Poly R - 478. Lett. Appl. Microbiol., 23: 93-96.

Coll, P.M., Abalos, J.M.F., Villanueva, J.R., Santamaria, R., Perez, P. 1993. Purification and characterization of Phenoloxidase (Laccase) from the Lignin-Degrading Basidiomycete PM1(CECT 2971). Appl. Environ. Microbiol., 59: 2607-2613.

D’Souza, T.M., Merrit, C.S., Reddy, C.A. 1999. Lignin modifying enzymes of the white rot basidiomycete 
Ganoderma lucidum. Appl. Environ. Microbiol., 65: 5307-5313.

De Jong, E., de Vries, F.P., Field, J.A., van der Zwan, R.P., de Bont, J.A.M. 1992. Isolation and screening of basidiomycetes with high peroxidative activity. Mycol. Res., 12: 1098-1104.

Dec, J., Bollag, J.M. 1994. Effect of various factore on halogenation of chlorinated phenols and anilines during oxidative coupling. Environ. Sci. Technol., 29: 657-663.

Duran, N., Rosa, M.A., D'Annibale, A., Gianfreda, L. 2002. Applications of laccases and tyrosinases (phenoloxidases) immobilized on different supports: a review. Enz. Microb. Technol., 31: 907-931.

Fernandez, L.J., Stahl, U. 1996. Isolation and characterization of a laccase gene from Podospora anserina. Mol. Gen. Genet., 252: 539-551.

Gold, M.H., Glenn, J.K., Alic, M. 1988. Use of polymeric dyes in lignin biodegradation assays. Methods in Enzymol., 161: 74-78.

Harkin, J.M., Obst, J.R. 1973. Syringaldazine, an effective reagent for detecting laccase and peroxidase in fungi. Experientia, 29: 381-387.

Hoegger, P.J., Kilaru, S., James, T.Y., Thacker, J.R., Kues, U. 2006. Phylogenetic comparison and classification of laccase and related multicopper oxidase protein sequences. FEBS J., 273: 2308-2326.

Jia Li Dong. 2004. Influence of culture conditions on laccase production and isoenzyme pattern in the white rot fungus Trametes gallica. J. Basic Microbiol., 45: 190-198.

Kiiskinen, L.L., Viikari, L., Kruus, K. 2002. Purification and characterization of a novel laccase from the ascomycete Melanocarpus albomyces. Appl.
Microbiol. Biotechnol., 59: 198-204. Liers, C., Ullrich, R., Pecyna, M., Schlosser, D., Hofrichter, M. 2007. Production, purification and partial enzymatic and molecular characterization of a laccase from the wood-rotting ascomycete Xylaria polymorpha. Enzyme Microb. Technol., 41: 785793.

Luterek, J., Gianfreda, L., WojitasWasilewska, M., Cho, N.S., Rogalski, J., Jaskek, H., Malarczyk, E., Staszczak, M., Fink-Boots, M. 1998. Activity of free and immobilized extracellular Cerrena unicolor laccase in water miscible organic solvents. Holzforschung, 52: 589-595.

Nishida, T., Yoshinori, K., Mimura, A., Takahara, Y. 1988. Lignin biodegradation by wood-rotting fungi I. Screening of lignindegrading fungi. Mokuzai Gakkaishi, 34: 530536.

Raghukumar, C., D'Souza, T.M., Thorn, R.G., Reddy, C.A. 1999. Ligninmodifying enzymes of Flavodon flavus, a basidiomyceteisolated from a coastal marine environment. Appl. Environ. Microbiol., 65: 2103-2111.

Tanaka, T., Tonosaki, T., Nose, M., Tomidokoro, N., Kadomura, N., Fujii, T., Taniguchi, M. 2001. Treatment of model soils contaminated with phenolic endocrine-disrupting chemicals with laccase from Trametes sp. in a rotating reactor. J. Biosci. Bioeng., 92: 312-316.

Tetsch, L., Bend, J., Hölker, U. 2006. Molecular and enzymatic characterisation of extra and intracellular laccases from the acidophilic ascomycete Hortaea acidophila. Anton. Van Leeuw, 90: 183-194. 
Thakker, G.D., Evans, C.S., Rao, K.K. 1992. Purification and characterization of laccase from Monocillium indicum Saxena. Appl. Micro. Biotechnol.,
37: 321-323.

Vogel, H.J. 1956. A convenient growth medium for Neurospora (Medium N). Microbial Genetics Bull., 13: 42-43.

\section{How to cite this article:}

Sheena Devasia and A. Jayakumaran Nair. 2016. Screening of Potent Laccase Producing Organisms Based on the Oxidation Pattern of Different Phenolic Substrates. Int.J.Curr.Microbiol.App.Sci. 5(5): 127-137. doi: http://dx.doi.org/10.20546/ijcmas.2016.505.014 